\title{
Application Of $\mathrm{Ba}_{0.5} \mathrm{Sr}_{0.5} \mathrm{TiO}_{3}$ (Bst) Film Doped With $\mathrm{RuO}_{2}$ $(0 \%, 2 \%, 4 \%$ and $6 \%)$ On A Rice-Stalk Cutting Robot Model Based On A Line Follower With Hc-05 Bluetooth Control
}

\author{
Ridwan Siskandar 1,*iD , Fabianus Chrisna Dio ${ }^{1}$, Husin Alatas ${ }^{2}$ (D), Irzaman Irzaman 2,* (D) \\ 1 Computer Engineering Study Program, College of Vocational Studies, IPB University, Bogor, West Java 16151, Indonesia \\ 2 Department of Physics, Faculty of Mathematics and Science, IPB University, Meranti Street, Dramaga, Bogor, West Java \\ 16680, Indonesia \\ * Correspondence: ridwansiskandar@apps.ipb.ac.id (R.S.); irzaman@apps.ipb.ac.id (I.);
}

Scopus Author ID 57188999030

Received: 11.04.2021; Revised: 18.05.2021; Accepted: 24.05.2021; Published: 18.06.2021

\begin{abstract}
Ba}_{0.5} \mathrm{Sr}_{0.5} \mathrm{TiO}_{3}$ (BST) film doped with $\mathrm{RuO}_{2}$ with varying concentrations $(0 \%, 2 \%, 4 \%$, and $6 \%$ ) on a p-type (100) silicon substrate has been successfully grown using the Chemical Solution Deposition (CSD) method and spin coating at a rotational speed of $3000 \mathrm{rpm}$ for 30 seconds. The film on the substrate was then heated at $850{ }^{\circ} \mathrm{C}$ for 15 hours. $\mathrm{BST}$ film $+\mathrm{RuO}_{2}$ variations were characterized for their sensitivity as a light sensor. $\mathrm{BST}$ film $+\mathrm{RuO}_{2}$ variations were tested with a varied light source and reflective surface colors. Thin films have a range at the visible light wavelength, so LED lights were used as the light source in the present study. The light source selected was the blue LED because it had a high contrast in differentiating between dark and light-colored surfaces. Various electronic circuits assisted sensitivity characterization with the aim to produce a sensor that is highly sensitive to light. The response of BST film $+\mathrm{RuO}_{2}$ variations differed according to the $\mathrm{RuO}_{2}$ doping concentration. BST film doped with $\mathrm{RuO}_{2} 6 \%$ had a very good response to changes in light, so this film was applied as the line detector sensor in the line follower-based rice-stalk cutter model with an HC-05 Bluetooth control. Before being integrated with the microcontroller, the output voltage of the BST film was strengthened using an op-amp circuit so that the microcontroller could read the output voltage of the BST film.
\end{abstract}

Keywords: $\mathrm{Ba}_{0.55} \mathrm{Sr}_{0.45} \mathrm{TiO}_{3}$ (BST) film; $\mathrm{RuO}_{2}$; line detector; op-amp; microcontroller.

(C) 2021 by the authors. This article is an open-access article distributed under the terms and conditions of the Creative Commons Attribution (CC BY) license (https://creativecommons.org/licenses/by/4.0/).

\section{Introduction}

Rice (Oryza sativa) is the most popular food crop in Indonesia. Most Indonesians consume rice which grows on rice stalks. The processing of rice is conducted through several stages, from the cutting of rice stalks to separate the rice grains from the stalks to the packing stage [1]. The majority of Indonesian farmers process rice manually. Therefore, automated rice processing tools are needed to accelerate productivity and to make the farmers' tasks easier and more efficient in both quality and effectiveness.

A robot is a machine designed to reduce the human workload. Robots are usually developed to reduce the risk factor and increase convenience in a certain job [2].

Line follower robots can be applied in various fields, including agriculture, especially in the automatization of rice production. A line follower robot can be made into a rice-stalk 
cutting tool by adding blades to two sides for cutting rice stalks and using a motor to move the blades so that cutting rice stalks would be faster, more efficient, and could be done automatically [3].

In the present day, technology in the field of materials has advanced quickly, including the field of electronic materials. One of the studies that has garnered much attention is the study of the ferroelectric material Barium Strontium Titanate (BST) doped with a variety of dopes (one of them being $\mathrm{RuO}_{2}$ ) which is then applied as a sensor or detector [4-20].

The explanation above has motivated the writers to create an application of $\mathrm{Ba}_{0.5} \mathrm{Sr}_{0.5} \mathrm{TiO}_{3}$ (BST) film doped with $\mathrm{RuO}_{2}(0 \%, 2 \%, 4 \%$, and 6\%) rice-stalk cutter model based on a line follower controlled by HC-05 Bluetooth.

\section{Materials and Methods}

\subsection{Research methodology.}

The procedure for this study was divided into two parts: (1) the production and characterization of $\mathrm{BST}$ film $+\mathrm{RuO}_{2}$ and the assembly of the rice-stalk cutting robot. Figure 1 presents the research diagram.

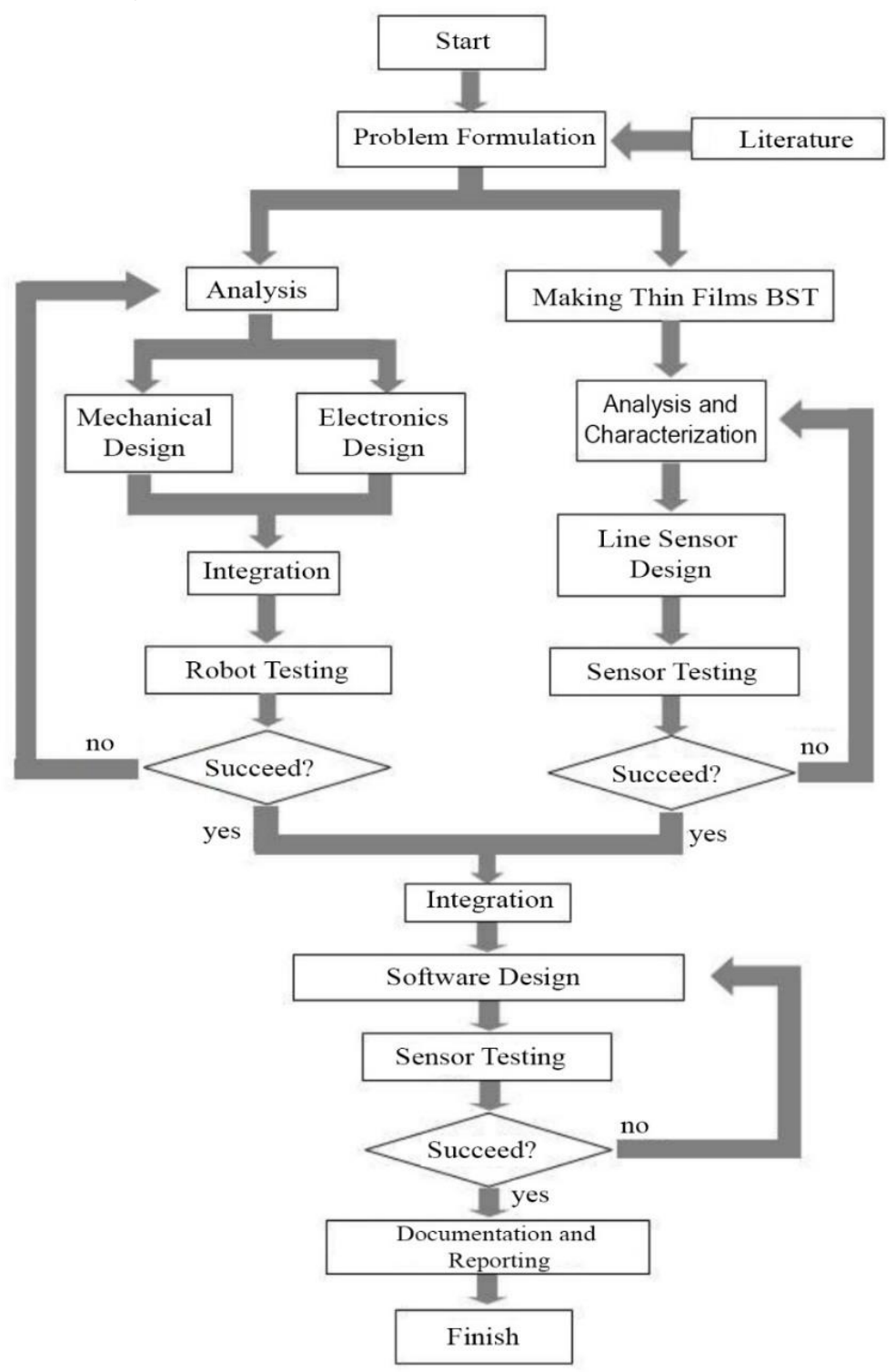

Figure 1. The research diagram. 
2.1.1. The P-type (100) silicon substrate preparation.

In this study, the substrate used was p-type silicon (100) substrate. The substrate that was originally a circle was cut into pieces with a size of $1 \mathrm{x} 1 \mathrm{~cm} 2$ to form a square, as shown in Figure 2. The p-type silicon substrate (100) that had been cut was then washed using a mixture of $5 \%$ concentration of fluid acid (HF) and $2 \%$ concentration of distilled water $[10,11$, 21].

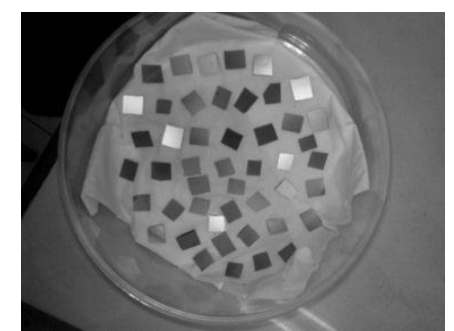

Figure 2. P-type (100) silicon substrate that had been cut into $1 \mathrm{x} 1 \mathrm{~cm}^{2}$ squares.

2.1.2. The Preparation of the $\mathrm{Ba}_{0.5} \mathrm{Sr}_{0.5} \mathrm{TiO}_{3}$ film Solution doped with $\mathrm{RuO}_{2}$.

The method used to make a $\mathrm{Ba}_{0,5} \mathrm{Sr}_{0,5} \mathrm{TiO}_{3}$ film solution doped with $\mathrm{RuO}_{2}$ is the CSD method. The composition of the $\mathrm{Ba}_{0,5} \mathrm{Sr}_{0,5} \mathrm{TiO}_{3}$ solution is made of $0.3512 \mathrm{~g}$ of Barium Acetate $\left[\mathrm{Ba}\left(\mathrm{CH}_{3} \mathrm{COOH}\right)_{2}, 99 \%\right], 0.2314 \mathrm{~g}$ of Strontium Acetate $\left.\left[\mathrm{Sr}\left(\mathrm{CH}_{3} \mathrm{COOH}\right)_{2}, 99 \%\right)\right], 0.7105 \mathrm{~g}$ of Titanium Isopropoxide [ $\left.\mathrm{Ti}\left(\mathrm{C}_{12} \mathrm{O}_{4} \mathrm{H}_{28}\right), 99 \%\right]$, and $2.5 \mathrm{ml}$ of 2-methoxy ethanol $\left[\mathrm{H}_{3} \mathrm{COOCH}_{2} \mathrm{CH}_{2} \mathrm{OH}, 99 \%\right]$ as solvents. After the solution mixture is formed, then the solution is sonicated using an ultrasonic device (Branson 2210 model). The sonication process was carried out for 1 hour. The resulting sonicated solution is called a precursor $[10,11,22,23]$.

\subsubsection{Growing the $\mathrm{Ba}_{0.5} \mathrm{Sr}_{0.5} \mathrm{TiO}_{3}$ film doped with $\mathrm{RuO}_{2}$.}

The growth of the $\mathrm{RuO}_{2}$ doped $\mathrm{Ba}_{0,5} \mathrm{Sr}_{0,5} \mathrm{TiO}_{3}$ film was carried out after the precursor solution was formed. The tool used in the process of growing the $\mathrm{Ba} 0,5 \mathrm{Sr} 0,5 \mathrm{TiO} 3$ film doped $\mathrm{RuO} 2$ is a spin coating reactor. In principle, first: P-type Silicon substrate (100) which has been cut to a size of $1 \times 1 \mathrm{~cm} 2$ and washed with a mixture of $5 \%$ concentration of fluid acid (HF) and $2 \%$ concentration of distilled water then placed on a spin coating reactor plate with $1 / 3$ part. The surface of the substrate is covered with a solution so that it is not exposed to the precursor solution when $2 / 3$ of the substrate is dripped with the precursor solution. Second: the precursor solution given to $2 / 3$ parts of the substrate is 3 drops. Third: the spin coating reactor is rotated at a rotating speed of 3000 radians per minute for 0.5 minutes. The second and third steps are carried out 3 times with a break for each repetition of 1 minute $[10,22,24,25]$.

\subsubsection{The annealing process.}

Annealing is a process of diffusing/activating a precursor solution with a substrate. In this study, annealing was carried out using a furnace (model VulcanTM-3-130). The annealing process is shown in Figure 3. Figure 3 explains that the annealing process starts from room temperature to annealing temperature of $850{ }^{\circ} \mathrm{C}$ (increase in annealing temperature: $1.7{ }^{\circ} \mathrm{C} /$ minute). The annealing temperature was held for 15 hours. After being held for 15 hours, the furnace cooling process is carried out for 12 hours until room temperature is recovered $[4,14$, 18, 26, 27]. The annealing process is shown in Figure 3. 


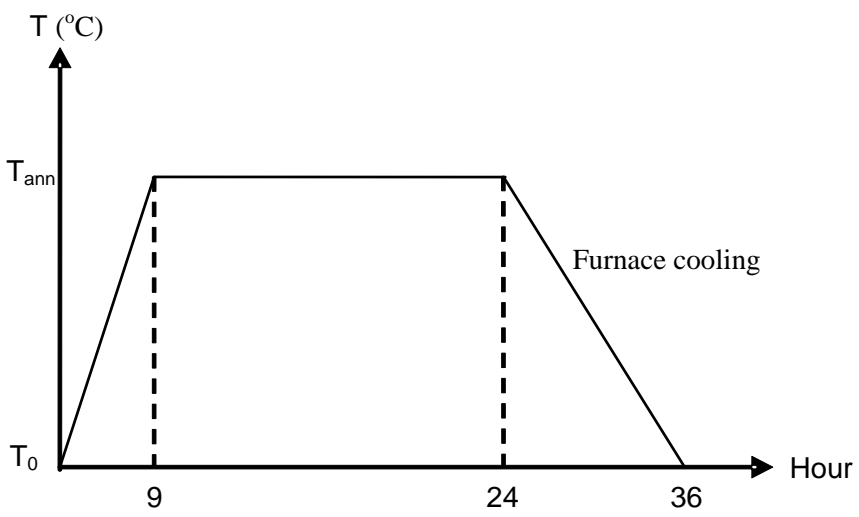

Figure 3. The annealing process.

2.1.5. The Installation of a contact in the $\mathrm{Ba}_{0.5} \mathrm{Sr}_{0.5} \mathrm{TiO}_{3}$ Film Doped with $\mathrm{RuO}_{2}$.

The making of contact film $\mathrm{Ba}_{0,5} \mathrm{Sr}_{0,5} \mathrm{TiO}_{3}$ doped $\mathrm{RuO}_{2}$ was carried out through the aluminum (Al) metallization process, as shown in Figure 4. The Al metallization process was carried out by evaporation in a vacuum air space. After the metallization process, the next step is making a hidden and installing a fine wire (made from plastic) using silver paste [10-12,21]. The model of $\mathrm{Ba} 0.5 \mathrm{Sr}_{0.5} \mathrm{TiO}_{3}$ film doped with $\mathrm{RuO}_{2}$ and the results of copper wire installation are shown in Figure 5.

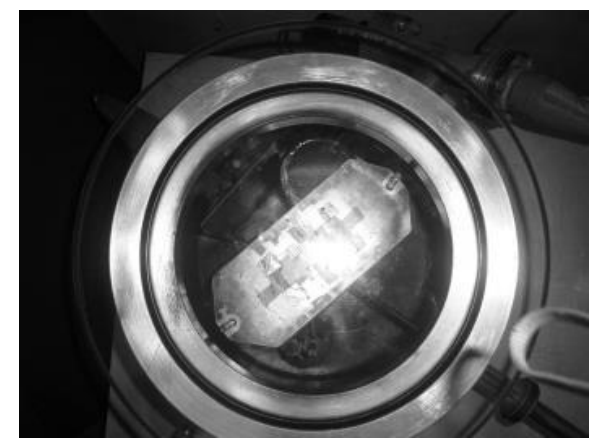

Figure 4. The aluminum metallization process as the film contact medium.

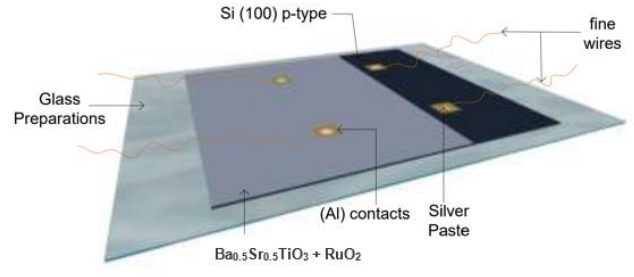

(a)

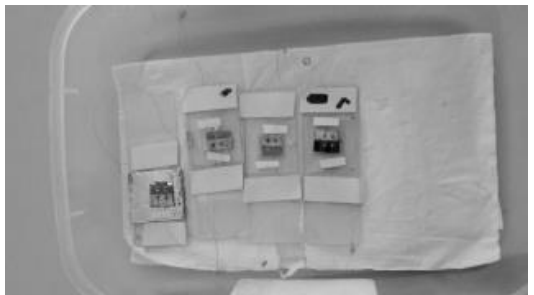

(b)

Figure 5. (a) The $\mathrm{Ba}_{0.5} \mathrm{Sr}_{0.5} \mathrm{TiO}_{3}$ film doped with $\mathrm{RuO}_{2}$ model; (b) The copper wire installation result.

2.1.6. The robot mechanics assembly.

The robot's body and frame were made from a plastic square sized $5 \mathrm{~cm} \times 15 \mathrm{~cm} \times 5$ $\mathrm{cm}$. The robot's body was made into two levels; the first level was on the bottom and functioned as the sensor base, where two line sensors were placed in the bottom of the forepart of the robot. The motor, gearbox, and power supply were placed in the first level. The second level was placed above the first level and functioned as the electronic circuit and microcontroller base. The rice-stalk cutting robot model design is presented in Figure 6. 


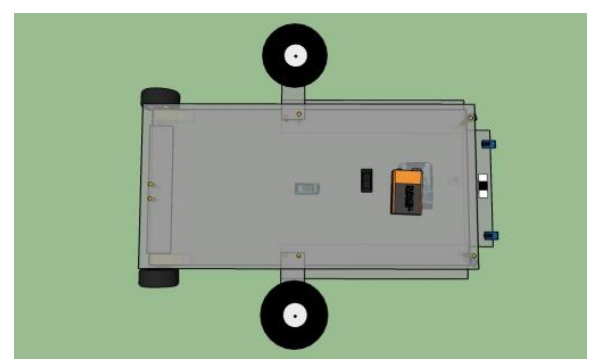

(a) Top view

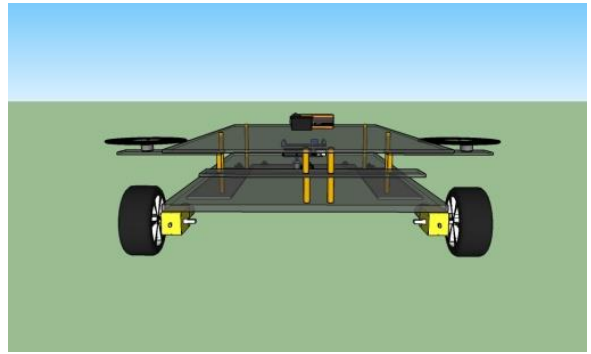

(c) Rear view

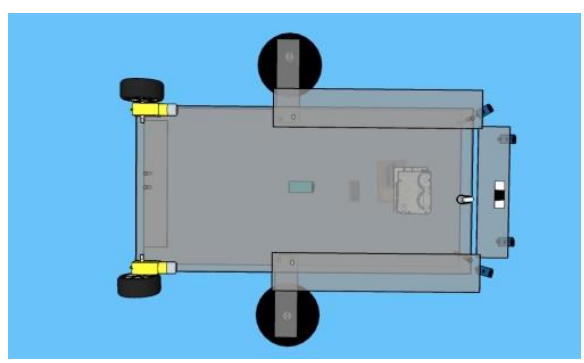

(b) Bottom view

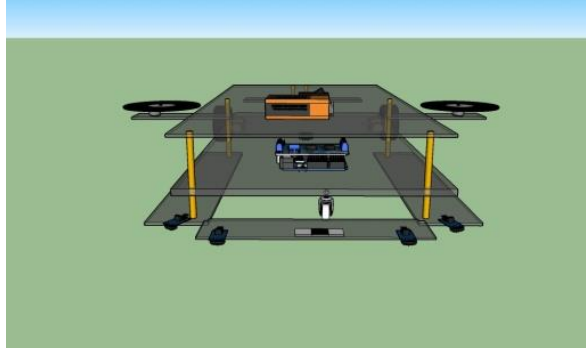

(d) Front view

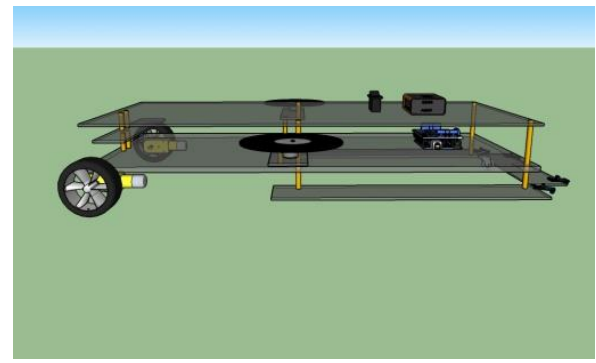

(e) Side view

Figure 6. The rice-stalk cutting robot model design.

\subsubsection{The production of electronic components.}

This stage included the assembly of the line sensor circuit and drive motor circuit. The line sensor circuit consisted of $2 \mathrm{BST}+\mathrm{RuO}_{2}$ thin film pieces, hooked up with a Wheatstone bridge circuit to increase the sensor's sensitivity. The output voltage signal from the Wheatstone bridge was amplified by an op-amp circuit. The op-amp used was an LM-324 IC. An L293D IC was used to operate the DC motor. One L293 IC could control two DC motors at the same time. The L293D's working system gave control signals in the form of logic or a pulse to the input line. The circuitry diagram for the rice-stalk cutter based on a line follower controlled by Bluetooth is presented in Figure 7.

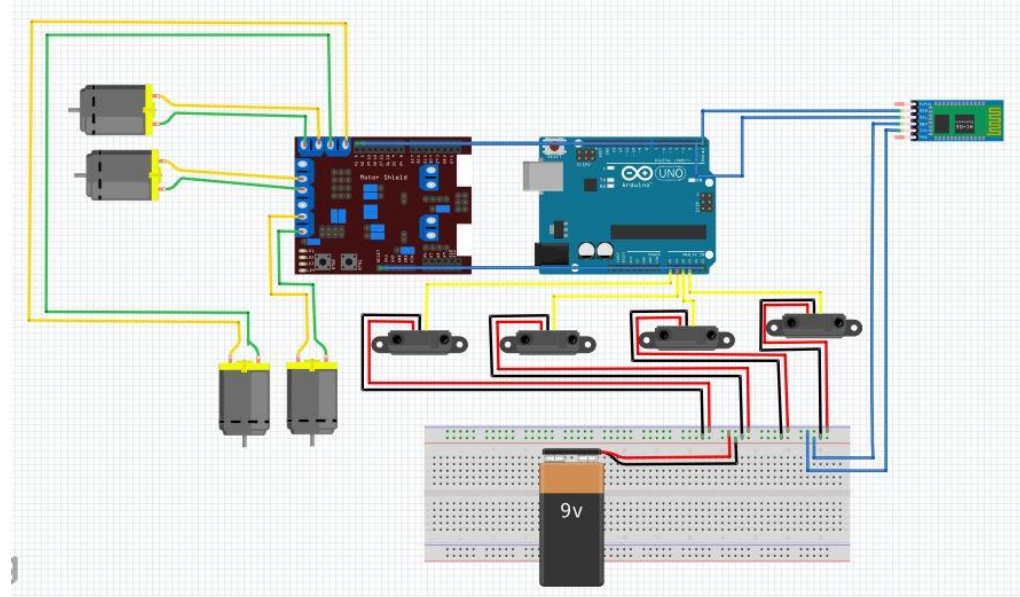

Figure 7. The circuitry diagram for the rice-stalk cutter based on a line follower controlled by Bluetooth. 


\subsubsection{Programming.}

The program was constructed using the IDE Arduino software. The programming language used was language $\mathrm{C}$.

2.1.9. Characterization of the $\mathrm{Ba}_{0.5} \mathrm{Sr}_{0.5} \mathrm{TiO}_{3}$ film doped with $\mathrm{RuO}_{2}$ as a line detector.

Characterization of the $\mathrm{Ba}_{0.5} \mathrm{Sr}_{0.5} \mathrm{TiO}_{3}$ film doped with $\mathrm{RuO}_{2}$ included the characterization of its sensitivity as a line detector sensor. The $\mathrm{Ba}_{0.5} \mathrm{Sr}_{0.5} \mathrm{TiO}_{3}$ film doped with $\mathrm{RuO}_{2}$ 's sensitivity as a line detector sensor was demonstrated by the difference between the output voltage and input voltage $(\Delta \mathrm{V} / \Delta \mathrm{I})$, with $\mathrm{V}$ as the output voltage and I like the input light intensity.

\section{Results and Discussion}

\section{1. $\mathrm{BST}$ film $+\mathrm{Ru} \mathrm{O}_{2}$ sensitivity test.}

In this study, a sensitivity test was carried out to get the best film. The best film is then used in the line follower robot. The electronic circuit for measuring the sensitivity of the BST $+\mathrm{RuO} 2$ film is arranged in series with one resistor. Furthermore, the circuit is paralleled with two resistors connected in series $[10,12,21]$. The series is usually referred to as a Wheatstone bridge series. The Wheatstone bridge series is shown in Figure 8.

In principle, measurements are made by providing a stimulus in the form of light. A good film will certainly respond to this stimulation by issuing an output in the form of a voltage. The process of measuring the film sensitivity test was carried out in 2 conditions, namely light ( \pm 637 lux $)$ and dark ( \pm 0 lux). The results of the measurement of the film sensitivity test are shown in Table 1 and Figure 9.

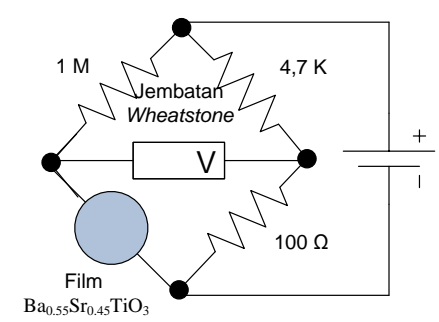

Figure 8. The Wheatstone circuit.

Table 1. The data from the measurement of the $\mathrm{BST}$ film $+\mathrm{RuO}_{2}{ }^{\text {' }} \mathrm{s}$ sensitivity as a light sensor.

\begin{tabular}{|c|c|c|c|c|c|c|c|}
\hline \multirow[b]{2}{*}{ Treatment } & \multirow{2}{*}{$\begin{array}{c}\mathrm{RuO}_{2} \\
\text { Concentration } \\
\text { Variation } \\
\end{array}$} & \multirow[b]{2}{*}{ Repetition } & & \multicolumn{4}{|c|}{ Sensitivity Measurement } \\
\hline & & & & $\begin{array}{c}\Delta \mathbf{V} \\
(\mathbf{m v})\end{array}$ & $\begin{array}{c}\Delta \mathbf{V} \\
(\mathbf{m v})\end{array}$ & $\begin{array}{c}\Delta I \\
\left(\operatorname{lux} / \mathbf{m}^{2}\right)\end{array}$ & $\Delta \mathbf{V} / \Delta \mathbf{I}$ \\
\hline \multirow{12}{*}{$\begin{array}{l}\text { Forward } \\
\text { Bias }\end{array}$} & \multirow{4}{*}{$\begin{array}{c}\text { Concentration } \\
0 \%\end{array}$} & \multirow{2}{*}{$\begin{array}{c}\text { Repetition } \\
1 \\
\end{array}$} & Dark & 36.00 & \multirow{2}{*}{35.00} & \multirow{2}{*}{637.00} & \multirow{2}{*}{0.05} \\
\hline & & & Bright & 71.00 & & & \\
\hline & & \multirow{2}{*}{$\begin{array}{c}\text { Repetition } \\
2\end{array}$} & Dark & 20.00 & \multirow{2}{*}{54.00} & \multirow{2}{*}{637.00} & \multirow{2}{*}{0.08} \\
\hline & & & Bright & 74.00 & & & \\
\hline & \multirow{4}{*}{$\begin{array}{c}\text { Concentration } \\
2 \%\end{array}$} & \multirow{2}{*}{$\begin{array}{c}\text { Repetition } \\
1 \\
\end{array}$} & Dark & 109.00 & \multirow{2}{*}{11.00} & \multirow{2}{*}{637.00} & \multirow{2}{*}{0.02} \\
\hline & & & Bright & 120.00 & & & \\
\hline & & \multirow{2}{*}{$\begin{array}{c}\text { Repetition } \\
2 \\
\end{array}$} & Dark & 127.00 & \multirow{2}{*}{47.00} & \multirow{2}{*}{637.00} & \multirow{2}{*}{0.07} \\
\hline & & & Bright & 174.00 & & & \\
\hline & \multirow{4}{*}{$\begin{array}{c}\text { Concentration } \\
4 \%\end{array}$} & \multirow{2}{*}{$\begin{array}{c}\text { Repetition } \\
1\end{array}$} & Dark & 10.00 & \multirow{2}{*}{4.00} & \multirow{2}{*}{637.00} & \multirow{2}{*}{0.01} \\
\hline & & & Bright & 14.00 & & & \\
\hline & & \multirow{2}{*}{$\begin{array}{c}\text { Repetition } \\
2\end{array}$} & Dark & 6.00 & \multirow{2}{*}{11.00} & \multirow{2}{*}{637.00} & \multirow{2}{*}{0.02} \\
\hline & & & Bright & 17.00 & & & \\
\hline
\end{tabular}




\begin{tabular}{|c|c|c|c|c|c|c|c|}
\hline \multirow{6}{*}{ Treatment } & \multirow{6}{*}{$\begin{array}{c}\mathrm{RuO}_{2} \\
\text { Concentration } \\
\text { Variation } \\
\\
\text { Concentration } \\
6 \%\end{array}$} & \multirow{4}{*}{$\begin{array}{c}\text { Repetition } \\
\text { Repetition } \\
1\end{array}$} & & \multicolumn{4}{|c|}{ Sensitivity Measurement } \\
\hline & & & & $\begin{array}{c}\Delta \mathbf{V} \\
(\mathbf{m v})\end{array}$ & $\begin{array}{c}\Delta \mathbf{V} \\
(\mathbf{m v})\end{array}$ & $\begin{array}{c}\Delta I \\
\left(\operatorname{lux} / \mathbf{m}^{2}\right)\end{array}$ & $\Delta \mathbf{V} / \Delta \mathbf{I}$ \\
\hline & & & Dark & 8.00 & \multirow{2}{*}{4.00} & \multirow{2}{*}{637.00} & \multirow{2}{*}{0.01} \\
\hline & & & Bright & 12.00 & & & \\
\hline & & \multirow[b]{2}{*}{$\begin{array}{c}\text { Repetition } \\
2\end{array}$} & Dark & 74.00 & \multirow[b]{2}{*}{84.00} & \multirow[b]{2}{*}{637.00} & \multirow[b]{2}{*}{0.13} \\
\hline & & & Bright & 158.00 & & & \\
\hline \multirow{16}{*}{ Reverse Bias } & \multirow{4}{*}{$\begin{array}{c}\text { Concentration } \\
0 \%\end{array}$} & Repetition & Dark & 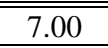 & \multirow{2}{*}{3.00} & \multirow{2}{*}{637.00} & \multirow{2}{*}{0.00} \\
\hline & & 1 & Bright & 10.00 & & & \\
\hline & & Repetition & Dark & 6.00 & & & \\
\hline & & 2 & Bright & 8.00 & 2.00 & 637.00 & 0.00 \\
\hline & & Repetition & Dark & 0.00 & 00 & 63700 & 000 \\
\hline & Concentration & 1 & Bright & 0.02 & 0.02 & 637.00 & 0.00 \\
\hline & & Repetition & Dark & 404.00 & & & \\
\hline & & 2 & Bright & 53.00 & 8.00 & 637.00 & 0.01 \\
\hline & & Repetition & Dark & 7.7 .00 & & 63700 & \\
\hline & Concentration & 1 & Bright & 17.00 & 10.00 & 637.00 & 0.02 \\
\hline & $4 \%$ & Repetition & Dark & 10.00 & 1300 & 63700 & 002 \\
\hline & & 2 & Bright & 23.00 & 13.00 & 637.00 & 0.02 \\
\hline & & Repetition & Dark & 120.00 & 1000 & 63700 & 002 \\
\hline & & 1 & Bright & 130.00 & 10.00 & & 0.02 \\
\hline & $6 \%$ & & Dark & 99.00 & 1200 & 63700 & 002 \\
\hline & & 2 & Bright & 111.00 & & & \\
\hline
\end{tabular}

The greater the intensity value is given, the more electrons are excited from the valence band to the conduction band. This proves that the excited electrons from the valence band to the conduction band will increase the charge carrier, thus increasing the value of the electrical conductivity [16, 28-30].

The film's sensitivity as a light sensor is demonstrated by the ratio between the voltage difference and the intensity difference $(\Delta \mathrm{V} / \Delta \mathrm{I})$. The greater the voltage difference, the more sensitive the film is. Table 1 showed that the measurement with the forward bias had a greater sensitivity value than the measurement with the reverse bias. This was because, during the forward bias condition (p-type Si was connected to V(+), type-n BST was connected to $\mathrm{V}(-)$ ), the charge would flow from the cathode to the anode, making the film act as a conductor.

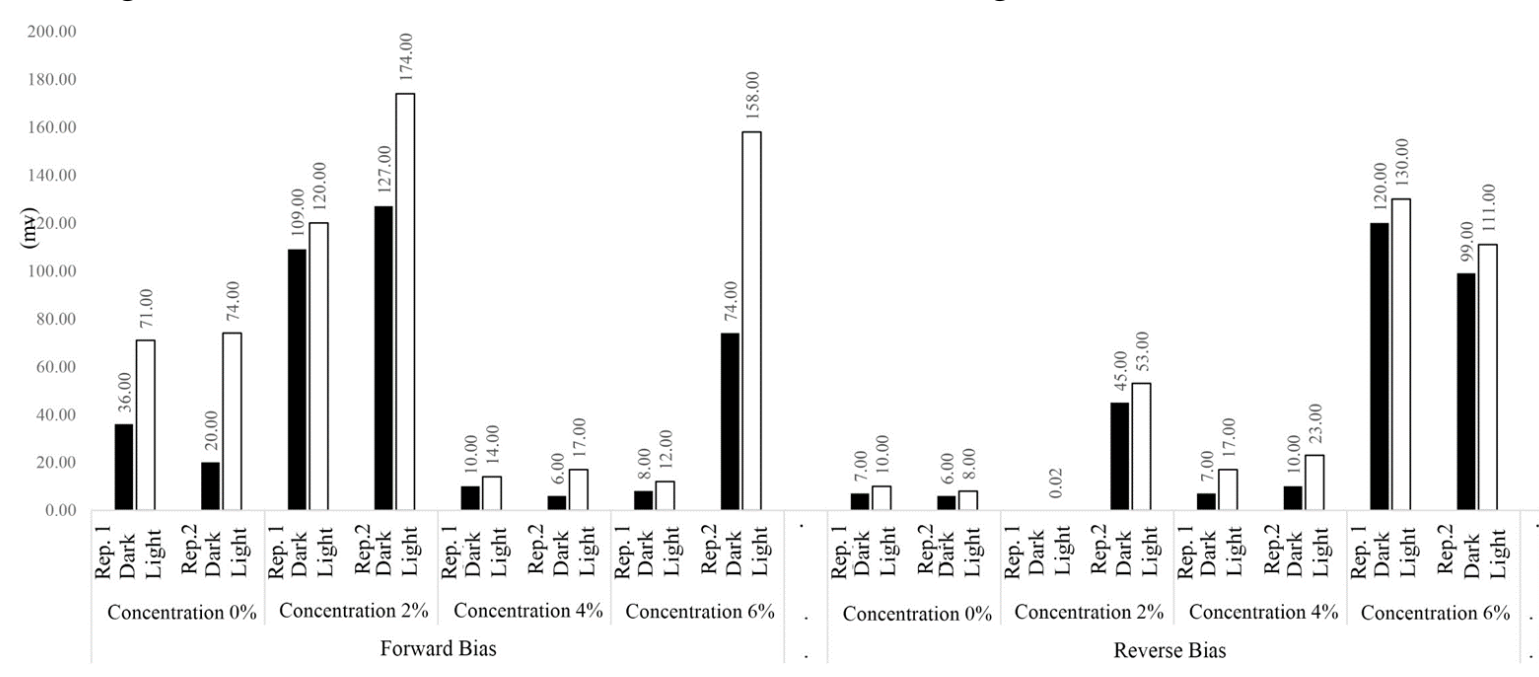

Note: Rep. $=$ Repetition

Figure 9. The graph for the measurement of the sensitivity of $\mathrm{BST}$ film $+\mathrm{RuO}_{2}$ as a light sensor.

3.2. Design of the $\mathrm{BST}$ film $+\mathrm{RuO}_{2} 6 \%$ as a line sensor. 
In this study, the line follower robot that was built consisted of 2 sensors, namely the 2 best films from sensitivity testing ( $\mathrm{BST}+\mathrm{RuO}_{2} 6 \%$ ). These sensors function as photodiodes that will read a line on the path. The results of the photodiode readings are used to determine the direction of motion of the robot. The measurement results in figure 10 show that the output voltage change of the $\mathrm{BST}+\mathrm{RuO}_{2}$ film $6 \%$ is still very small, so an amplifier circuit is needed so that the output of the change in voltage can be read by the microcontroller. The amplifier circuit used is shown in Figure 11 [10, 21].

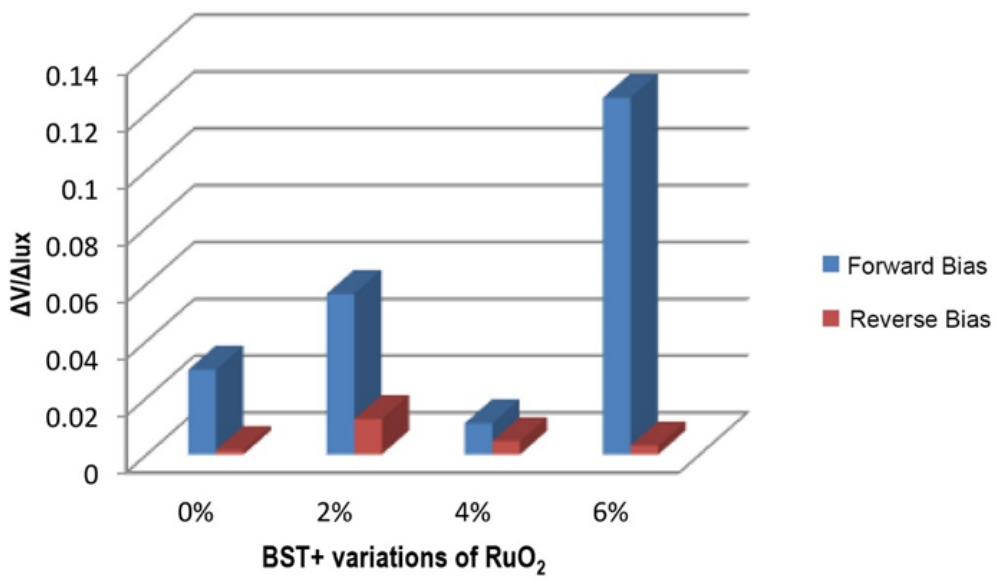

Figure 10. The sensitivity of $\mathrm{BST}+\mathrm{RuO}_{2}$ film $(\Delta \mathrm{V} / \Delta \mathrm{lux})$ in the forward bias circuit and the reverse bias circuit.

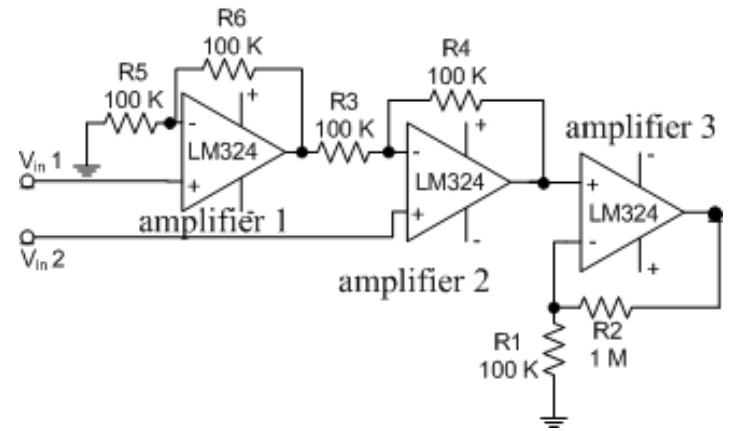

Figure 11. Amplifying circuit.

The first amplifying circuit was a differential amplifying circuit. A differential amplifying circuit is a circuit that compares two inputs. A differential circuit was used in the initial stage because the $\mathrm{BST}$ film $+\mathrm{RuO}_{2}$ was assembled with a Wheatstone bridge with two outputs, v1 and v2. The differential circuit was a combination between a non-inverting circuit (OpAmp 1) and an inverting circuit (OpAmp 2) [10,21]. The gain for the non-inverting circuit was:

$$
\frac{\text { Vout }}{\text { Vin }}=\left(1+\frac{R_{f}}{R_{\text {in }}}\right)
$$

Whereas for the inverting circuit, it was

$$
\frac{\text { Vout }}{\text { Vin }}=-\left(\frac{R_{f}}{R_{\text {in }}}\right)
$$

In the inverting circuit (OpAmp2), because the reference voltage was fed with a positive reference voltage (v2), the gain would positively value. Therefore, the total gain for the differential circuit was:

$$
\begin{aligned}
\frac{\text { Vout }}{\text { Vin }} & =\left(1+\frac{R_{f}}{R_{\text {in }}}\right)\left(\frac{R_{f}}{R_{\text {in }}}\right) \\
& =\left(1+\frac{R_{6}}{R_{5}}\right)\left(\frac{R_{4}}{R_{3}}\right)
\end{aligned}
$$




$$
\begin{aligned}
& =\left(1+\frac{100 k}{100 k}\right)\left(\frac{100 k}{100 k}\right) \\
& =2 \text { times. }
\end{aligned}
$$

For the second amplifying circuit, the non-inverting amplifying circuit (OpAmp 3), the gain was:

$$
\begin{aligned}
\frac{\text { Vout }}{\text { Vin }} & =\left(1+\frac{R_{f}}{R_{\text {in }}}\right) \\
& =\left(1+\frac{R_{2}}{R_{1}}\right) \\
& =\left(1+\frac{1 M}{100 k}\right) \\
& =11 \text { times }
\end{aligned}
$$

The $\mathrm{BST}+\mathrm{RuO}_{2}$ 's working principle as a line detector was capturing the intensity of the LED light reflected by the reflective surface. The more light is reflected, the greater the intensity captured by the $\mathrm{BST}$ film $+\mathrm{RuO}_{2}$ is, causing the output voltage to become greater. On the other hand, the less light is reflected, the less light is captured by the BST film+RuO 2 , and the output voltage would be smaller. This study employed LED color and reflective surface variations.

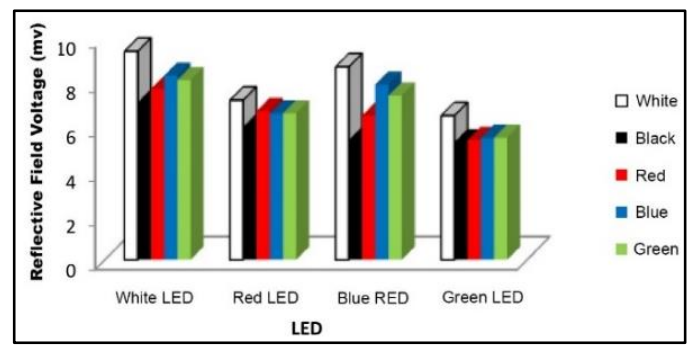

Figure 12. The film's output voltage with LED color and reflective surface variations.

This study used a $5 \mathrm{~mm}$-diameter LED as the light source because LEDs produce light in the visible lightwave range. The LEDs used were white, blue, red, and green. LED lights were selected because LEDs have a focused, high light intensity. Based on the measurements using a Luxmeter, the intensity of the white LED was 1880 lux, the red LED 438 lux, the blue LED 814 lux, and the green LED 1232 lux. The intensity measurements of each color LED were taken at a voltage of 5 volts and a 330-ohm resistor. The reflective test surfaces were white, black, red, blue, and green.

Figure 12 demonstrates that the white reflective surface produced the largest output voltage for all the LEDs, and the black reflective surface produced the smallest output voltage. This is because the white reflective surface would reflect almost all lightwave lengths, causing the intensity received by the film to be greater. On the other hand, the black surface absorbs nearly all lightwave lengths, causing less light to be received by the film.

The red LED was found to have a high voltage on the red reflective surface which was second only to the white surface. This is because the red surface would reflect red light and absorb all other light. The red LED emits red light, which is reflected by the red surface, so much light was captured by the film on the red surface. This is similar to the blue and green LEDs, which would have a greater output voltage on the reflective surface with the same color 
as its light source. The blue LED had the greatest voltage difference for each of the reflective surfaces among all the LEDs; therefore, the present study employed a blue LED as the light source in the line sensor circuit.

\subsection{The DC driver motor circuit.}

The DC driver motor circuit consisted of an L293D IC. The movement of the two motors was determined by the input to the IC. The motor speed was controlled by the variations in pulse width fed by the microcontroller as the PWM input. The test results demonstrated that there are a number of possible input conditions that could be given and the motor movement directions. Table 2 presents the results for the input and output possibilities.

Table 2. Results of the input testing on the motor driver and the motor movement directions.

\begin{tabular}{c|c|c|c|c|c}
\multicolumn{7}{c|}{ Input } & \multirow{2}{*}{ Hex } & \multirow{2}{*}{ Output } \\
\cline { 1 - 3 } Input 1 & Input 2 & Input 3 & Input 4 & & Left Motor Forward \\
\hline 0 & 0 & 1 & 0 & 02 & Left Motor Reverse \\
\hline 0 & 0 & 0 & 1 & 01 & Right Motor Forward \\
\hline 0 & 1 & 0 & 0 & 04 & Right Motor Reverse \\
\hline 1 & 0 & 0 & 0 & 08 & Forward \\
\hline 0 & 1 & 1 & 0 & 06 & Reverse
\end{tabular}

\subsection{Circuit control system.}

The circuit to control the system was a 10 bit Atmega328 (Arduino Uno) microcontroller, which would control the supporting circuit in the line follower system. The output voltage from the line sensor circuit was the input signal for the microcontroller. The analog signal from the sensor needs to be converted into a digital signal by the ADC, which has been integrated into the Atmega328 microcontroller so that the microcontroller can enter it.

The voltage output from the sensor was not constant, so the microcontroller could not have the voltage reference value directly used to compare bright and dark conditions. To be able to differentiate lines, first, the line follower is placed on a white surface white, and the microcontroller would read the input voltage. The initial voltage would be translated as the sensor is on a white surface. If the input voltage experiences a significant decrease, the microcontroller would conclude that the sensor is on a black surface. The microcontroller would then give instructions to the two motors as a response to the input given.

The circuit assembly pattern was made based on the circuit pattern diagram that had been previously designed (Figure 7). The circuit control system assembly process is shown in Figure 13 and Figure 14.
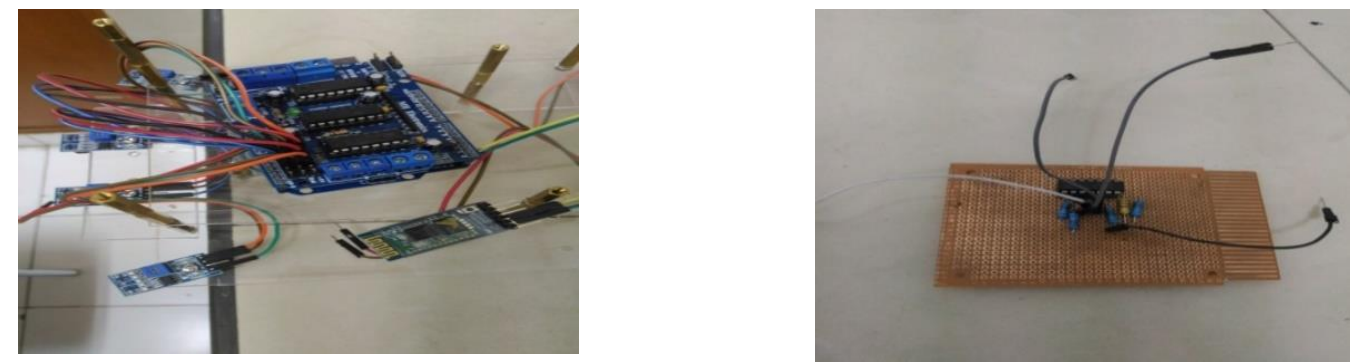
Figure 13. The system controlling the circuit assembly process.

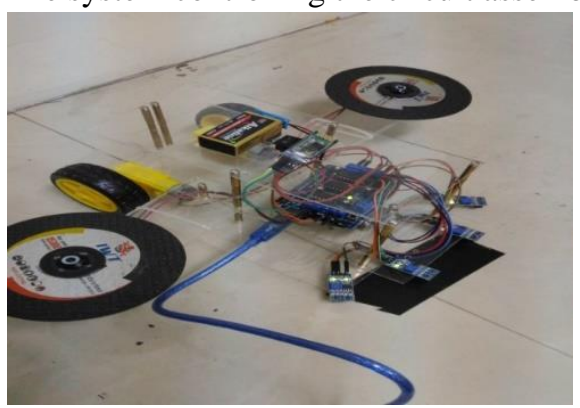

Figure 14. The appearance of the bluetooth-controlled line follower-based rice-stalk cutter model.

\subsection{The application programming.}

The programming process used the AppInventor software because it was easier to use and had a fairly attractive user interface display. The functions and elements in the code program were made based on the entity in the application's flowchart and used the while-do logic for each condition. The AppInventor supports the use of a Bluetooth connection, and the output in this program is a .apk, which could be used directly on a smartphone with an Android operating system. The coding program is presented in Figure 15. The display of the line follower rice-stalk cutter application is presented in Figure 16.
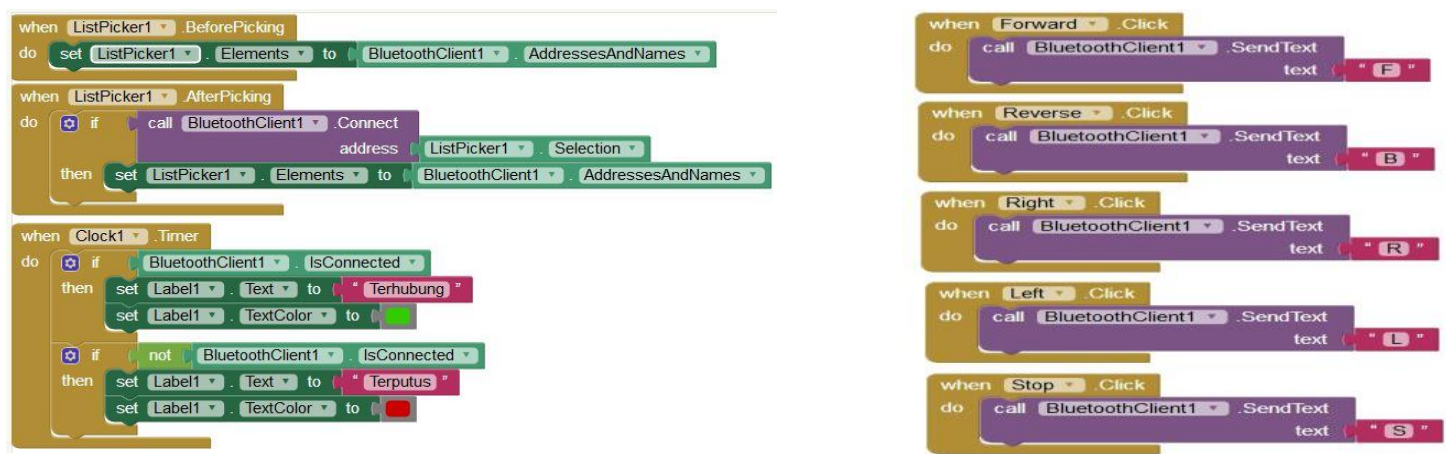

Figure 15. The application code program for the rice-stalk cutter based on a line follower controlled via Bluetooth.

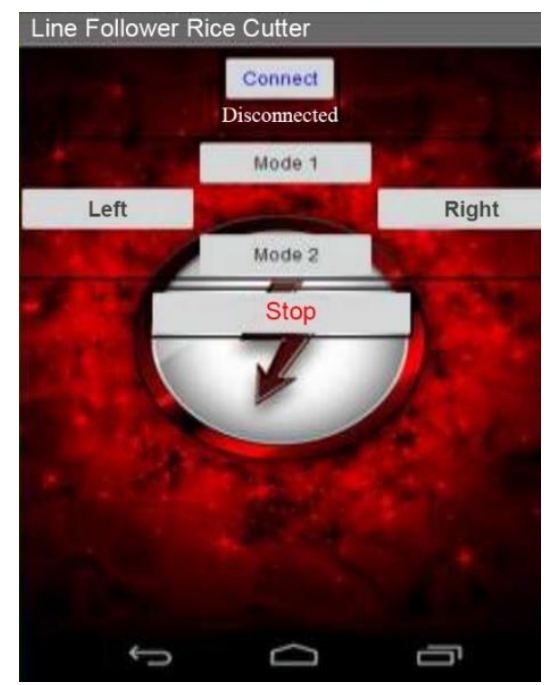

Figure 16. The display for the rice-stalk cutter line follower application.

3.6. Testing. 
Overall testing was conducted on the design that had been integrated as a line follower robot. The testing was a functional test on the sensor and the robot. The robot would run on a black path on a white surface, controlling the movements to the right or left. Table 3 and Table 4 present the results for the functional test on the sensor and the functional test on the robot with variations in turning angles.

Table 3. The results of the functional sensor test.

\begin{tabular}{l|l|l|l} 
No & Testing Scenario & The expected outcome & Test Result \\
\hline 1 & Both sensors on a white surface. & Both wheels move forward & Success \\
\hline 2 & $\begin{array}{l}\text { The right sensor on a white surface, and the } \\
\text { left sensor on a black surface }\end{array}$ & $\begin{array}{l}\text { The right wheel moves forward, and the } \\
\text { left wheel does not move. }\end{array}$ & Success \\
\hline 3 & $\begin{array}{l}\text { The right sensor on a black surface, and the } \\
\text { left sensor on a white surface }\end{array}$ & $\begin{array}{l}\text { The right wheel does not move, and the } \\
\text { left wheel moves forward }\end{array}$ & Success \\
\hline 4 & Both sensors on a black surface & Both wheels do not move. & Success
\end{tabular}

Table 4. The results of the robot functional with turning angle variations.

\begin{tabular}{c|c|c|c}
\multirow{2}{*}{ No } & \multirow{2}{*}{ Turning angle } & \multicolumn{2}{|c}{ Test Result } \\
\cline { 3 - 4 } & $0^{0}$ & Turn right & Turn Left \\
\hline 1 & $10^{0}$ & Success & Success \\
\hline 2 & $20^{0}$ & Success & Success \\
\hline 3 & $30^{0}$ & Success & Success \\
\hline 4 & $40^{0}$ & Success & Success \\
\hline 5 & $50^{0}$ & Success & Success \\
\hline 6 & $60^{0}$ & Success & Success
\end{tabular}

\section{Conclusions}

The $\mathrm{BST}+\mathrm{RuO}_{2}$ thin-film demonstrated changes in electric conductivity when the intensity of light that fell on the film changed. Based on the sensitivity test, BST film $+\mathrm{RuO}_{2}$ $6 \%$ was the best film. Therefore, this film was applied as a line detector in the line follower.

An Atmega328 (Arduino Uno) microcontroller was used to control the robot. The input for the microcontroller was the voltage drop difference in the film due to changes in light intensity. The differences in the voltage drop were very small, so they needed to be amplified using operational amplifying circuits. The amplifying circuits used in this study were a differential amplifying circuit and a non-inverting amplifying circuit. The microcontroller gave instructions to the two motors as a response to the input given. The film had an absorbance range at the visible lightwave length; therefore, the present study used an LED light as the light source. The light source was a blue LED $(450-495 \mathrm{~nm})$ because it had a high contrast for differentiating dark and bright-colored surfaces.

\section{Funding}

This research received no external funding.

\section{Acknowledgments}

We gratefully acknowledge the funding from Hibah Program Penelitian Terapan Unggulan Perguruan Tinggi (PTUPT) with grant number 1/E/KP.PTNBH/2021 dated march 8, 2021, KemenristekBrin Republik Indonesia.

\section{Conflicts of Interest}

The authors declare no conflict of interest. 


\section{References}

1. Shoji, K.; Itoh, K.; Kawahara, F.; Yoshida, Y.; Yamamoto, Y.; Sudo, K.I. Micro-elevations in paddy fields affect the efficacy of mechanical weeding: Evaluation of weeding machines to control Monochoria vaginalis in herbicide-free farming. Weed Biol. Manag. 2013, 13, 45-52, https://doi.org/10.1111/wbm.12011.

2. Besari, A.R.A.; Sukaridhoto, S.; Wibowo, I.K.; Berlian, M.H.; Akbar, M.A.W.; Yohanes Yohanie, F.P.; Aldi Bayu, K.I. Preliminary design of interactive visual mobile programming on educational robot ADROIT V1. Proc. - $2016 \quad$ Int. Electron. Symp. IES $2016 \quad$ 2017, 499-503, https://doi.org/10.1109/ELECSYM.2016.7861057.

3. Loria, A.; Dasdemir, J.; Alvarez Jarquin, N. Leader-Follower Formation and Tracking Control of Mobile Robots Along Straight Paths. IEEE Trans. Control Syst. Technol. 2016, 24, 727-732, https://doi.org/10.1109/TCST.2015.2437328.

4. Irzaman; Nuraisah, A.; Aminullah; Hamam, K.A.; Alatas, H. Optical properties and crystal structure of lithium doped $\mathrm{Ba} 0.55 \mathrm{Sr} 0.45 \mathrm{TiO} 3$ (BLST) thin films. Ferroelectr. Lett. Sect. 2018, 45, 14-21, https://doi.org/10.1080/07315171.2018.1499361.

5. Irzaman; Sitompul, H.; Masitoh; Misbakhusshudur, M.; Mursyidah. Optical and structural properties of lanthanum doped lithium niobate thin films. Ferroelectrics 2016, 502, 9-18, https://doi.org/10.1080/00150193.2016.1232579.

6. Mohammed, B.; Kaleli, M. Effect of Substrate and Annealing Ambient on the Conductivity of Sputtered MoSi2 Ceramic Thin Film. J. Electron. Mater. 2020, 49, 5570-5584, https://doi.org/10.1007/s11664-02008282-9.

7. Nanda, B.B.; Pradhan, M.; Kar, P.; Nanda, B. Apparent molar volume and coefficients of Jones-Dole equation for the evaluation of ion-solvent interactions of barium chloride in aqueous 1, 4-dioxane and ethylene glycol solutions at $\mathrm{T}=(298.15 \mathrm{~K}$ to 313.15$) \mathrm{K}$ and at atmospheric pressure. Biointerface Res. Appl. Chem. 2020, 10, 5901-5909, https://doi.org/10.33263/BRIAC104.901909.

8. Palupi, E.K.; Umam, R.; Andriana, B.B.; Sato, H.; Alatas, H.; Irzaman. Fabrication and analysis phonon mode of barium strontium titanate-chlorophyll thin film (chlorophyll extract: Green spinach, cassava, Green choy sum). AIP Conf. Proc. 2019, 2202, https://doi.org/10.1063/1.5141631.

9. Rahmawaty, V.; Siskandar, R.; Palupi, E.K.; Alatas, H.; Patonah, N.; Iqbal, M.; Yuliarto, B.; Fahmi, M.Z.; Rusydi, F.; Nugroho, W.S. The Effect of Photoconductive Mole Fraction Based on 0.500 ) on Electrical Properties and Diffusivity Coefficient. Biointerface Res. Appl. Chem. 2021, 11, 14956-14963.

10. Irzaman, R.S. Characterization of $\mathrm{Ba} 0.55 \mathrm{Sr} 0.45 \mathrm{TiO} 3$ films as light and temperature sensors and its implementation on automatic drying system model. Integrated Ferroelectrics 2016, 4587, https://doi.org/10.1080/10584587.2016.1159537.

11. Irzaman; Siskandar, R.; Yuliarto, B.; Zakki Fahmi, M.; Ferdiansjah. Application of Ba0.5Sr0.5TiO3 (Bst) Film Doped with 0\%, 2\%, 4\% and 6\% Concentrations of RuO2 as an Arduino Nano-Based Bad Breath Sensor. Chemosensors 2020, 8, 1-11, https://doi.org/10.3390/chemosensors8010003.

12. Siskandar, R.; Irmansyah; Irzaman. Sensor Suhu Berbasis Bahan Ferroelektrik Film Ba0,55 Sr0,45 Tio3 ( Bst ) Berbantukan Mikrokontroler Atmega 8535. Biofisika 2013, 9, 1-12.

13. Setiawan, A.; Palupi, E.K.; Umam, R.; Alatas, H.; Irzaman. Optical characterization of Ba0.5Sr0.5TiO3 material grown on a p-type silicon substrate (111) doped niobium oxide and chlorophyll. Ferroelectrics 2020, 568, 62-70, https://doi.org/10.1080/00150193.2020.1735893.

14. Irzaman; Prawira, D.S.; Irmansyah, I.; Yuliarto, B.; Siregar, U.J. Characterization of Lithium Tantalate $(\mathrm{LiTaO} 3)$ Film on the Concentration Variations of Ruthenium Oxide (RuO2) Dope. Integr. Ferroelectr. 2019, 201, 32-42.

15. Mulyadi; Wahyuni, R.; Hardhienata, H.; Irzaman. Barium strontium titanate thin film growth with variation of lanthanum dopant compatibility as sensor prototype in the satellite technology. IOP Conf. Ser. Earth Environ. Sci. 2018, 149, https://doi.org/10.1088/1755-1315/149/1/012069.

16. Kurniawan, A.; Irzaman; Yuliarto, B.; Fahmi, M.Z.; Ferdiansjah. Application of barium strontium titanate (BST) as a light sensor on led lights. Ferroelectrics 2020, 554, 160-171, https://doi.org/10.1080/00150193.2019.1684758.

17. Rahmawaty, V.; Palupi, E.K.; Patonah, N.; Sumaryada, T.; Irzaman. The mole fraction effect on magnetic properties of baxsr1-xtio3 $(\mathrm{X}=0 ; 0.125 ; 0.25 ; 0.375 ; 0.500)$ thin film. Key Eng. Mater. 2020, 855 KEM, 197-201, https://doi.org/10.4028/www.scientific.net/KEM.855.197.

18. Anindy, U.; Nur Indro, M.; Husein, I. Piezoelectric properties: cerium oxide (CeO2) doped barium titanate (BaTiO3) film on ITO substrate. Ferroelectrics 2021, 570, 162-175, https://doi.org/10.1080/00150193.2020.1839267.

19. Szafraniak, B.; Fu, Ł. Semiconducting Metal Oxides: SrTiO 3, BaTiO 3 and BaSrTiO 3 in Gas-Sensing Applications: A Review. Coatings 2021, 11, 1-22, https://doi.org/10.3390/coatings11020185.

20. Arshad, M.; Du, H.; Javed, M.S.; Maqsood, A.; Ashraf, I.; Hussain, S.; Ma, W.; Ran, H. Fabrication, structure, and frequency-dependent electrical and dielectric properties of Sr-doped BaTiO3 ceramics. Ceram. Int. 2020, 46, 2238-2246, https://doi.org/10.1016/j.ceramint.2019.09.208. 
21. Irzaman; Siskandar, R.; Nabilah, N.; Aminullah; Yuliarto, B.; Hamam, K.A.; Alatas, H. Application of lithium tantalate (LiTaO3) films as light sensor to monitor the light status in the Arduino Uno based energysaving automatic light prototype and passive infrared sensor. Ferroelectrics 2018, 524, 44-55, https://doi.org/10.1080/00150193.2018.1432842.

22. Dahrul, M.; Syafutra, H.; Arif, A.; Irzaman; Indro, M.N.; Siswadi. Manufactures and Characterizations of Photodiode Thin Film Barium Strontium Titanate (BST) Doped by Niobium and Iron as Light Sensor. AIP Publishing 2013, 135, 43-46, https://doi.org/10.1063/1.4757185.

23. Crunteanu, A.; Muzzupapa, V.; Ghalem, A.; Huitema, L.; Passerieux, D.; Borderon, C.; Renoud, R.; Gundel, H.W. Characterization and Performance Analysis of BST-Based Ferroelectric Varactors in the MillimeterWave Domain. Crystals 2021, 11, https://doi.org/10.3390/cryst11030277.

24. Kurniawan, A.; Yosman, D.; Arif, A.; Juansah, J.; Irzaman. Development and Application of Ba0.5Sr0.5TiO3 (BST) Thin Film as Temperature Sensor for Satellite Technology. Procedia Environ. Sci. 2015, 24, 335-339, https://doi.org/10.1016/j.proenv.2015.03.044.

25. Faridawati, F.; Rohedi, A.Y.; Minarto, E.; Yudoyono, G.; Widihartanti, T.; Pramono, Y.; Yuningtyas, N. The Comparison of Optical Properties Between Ba0.25Sr0.75TiO3 and Ba0.75Sr0.25TiO3 Thin Films As The Light Sensors Application. J. Phys. Conf. Ser. 2021, 1825, 0-6, https://doi.org/10.1088/17426596/1825/1/012079.

26. Hamdani, A.; Komaro, M.; Irzaman. A synthesis of BaXSr1-xTiO3 film and characterization of ferroelectric properties and its extension as random access memory. Mater. Phys. Mech. 2019, 42, 131-140, https://doi.org/10.18720/MPM.4212019_11.

27. Boda, N.; Naidu, K.C.B.; Batoo, K.M.; Joice, G.H.R.; Naik, J.L.; Ravinder, D. Structural, morphological and electronic properties of cadmium cobalt ferrite nanoparticles. Biointerface Res. Appl. Chem. 2020, 10, 4752-4763, https://doi.org/10.33263/BRIAC101.752763.

28. Irzaman; Syafutra, H.; Darmasetiawan, H.; Hardhienata, H.; Erviansyah, R.; Huriawati, F.; Akhiruddin, A.; Hikam, M.; Arifin, P. Electrical Properties of Photodiode Ba0.25Sr0.75TiO3 (BST) Thin Film Doped with Ferric Oxide on p-type Si (100) Substrate using Chemical Solution Deposition Method. Atom Indones. 2011, 37, https://doi.org/10.17146/aij.2011.81.

29. Iskandar, J.; Jenie, R.P.; Siregar, U.J.; Yuliarto, B.; Irzaman. Application of thin film barium strontium titanate (BST) in a microcontroller based tool to measure oxygen saturation in blood. Ferroelectrics 2020 , 554, 134-143, https://doi.org/10.1080/00150193.2019.1684755.

30. Zaoui, M.; Sellami, B.; Boufahja, F.; Faloda, F.; Nahdi, S.; Alrezaki, A.; Alwasel, S.; Harrath, A.H. Effects of ferroelectric oxides of barium strontium titanate $(\mathrm{Ba} 0.85 \mathrm{Sr} 0.15 \mathrm{TiO} 3)$ nanoparticles on Ruditapes decussatus assessed through chemical, physiological, and biochemical methods. Chemosphere 2021, 265, https://doi.org/10.1016/j.chemosphere.2020.129078. 